\title{
Ornaments as Means of Efficient Reinforcement in
}

\section{Heritage Buildings}

\author{
Randa Hassan Mohamed ${ }^{1}$ and Abdu Wahab El-Khady ${ }^{2}$ \\ 1. Department of Architectural Engineering, the Higher Institute of Engineering, El Shorouk 002, Egypt \\ 2. Department of Architectural Engineering, Collage of Engineering and Technology, Arab Academy for Science, Technology and \\ Maritime Transport, Port Said 002, Egypt
}

\begin{abstract}
Heritage consists of those items people have inherited and want to keep, as they give them the sense of the past of their cultural identity, but these items, especially the buildings, could not face deteriorations during their period of life, such as the change of loads, the act of the environmental conditions, the effect of the duration time of the materials and the misuse of the occupants. They need special treatments and reinforcements to keep the structural state or to gain extra forces to receive the new loads. But the traditional ways of reinforcement do not prove endless solutions as the most means of the deteriorations from the nature. So, the liability issue is how to find the least reinforcement within the means of technology with the least deterioration and in a less time or by other ways efficiently. The hypothesis considers that the ornaments in some heritage buildings are found in critical levels of the construction which can share in an efficient way in the reinforcement processes of such buildings.
\end{abstract}

Key words: Ornaments, deterioration, heritage significance, efficient reinforcement, nano-materials.

\section{Introduction}

Ornaments represent important items in heritage buildings as they have the ability to demonstrate the past: they represent means of the archaeological remains which have special patterns of cultural history of local areas and they are important in demonstrating aesthetic characteristics and degree of creative or technical achievement in these areas. So they represent the real significance of the heritage buildings [1].

The ornaments vary from writings with especial kinds of art, fine gypsum patterns, fine timber details, crafts on masonries or special metallic ornaments. Also, they are found in various positions in the heritage building as they spread in the outer envelope or in the inner space. But using them in the proposed mission as means of reinforcement needs some studies to prove their effective share specially while using them within the new technologies which must not affect their

Corresponding author: Randa Hassan Mohamed, Dr., associate professor, research fields: heritage and environmental conservation.E-mail: dr.randa_hassan@yahoo.com. heritage significance.

So the paper will be divided into two parts to search for the accuracy of such hypothesis as follows:

(1) assessing the efficiency of the traditional ways of reinforcing the heritage elements of the buildings;

(2) assessing the role of the new technology in reinforcement and its relation to the ornaments.

\section{Efficiency of the Traditional Ways of Reinforcing the Heritage Elements of the Buildings}

Such part of the study will be divided into three part: redefining the efficiency of the heritage reinforcement, introducing the shapes of deterioration that need reinforcement and finally assessing the efficiency of the traditional ways of reinforcing the heritage elements of the buildings.

\subsection{Redefining the Efficiency of the Heritage Reinforcement}

In contrast to effectiveness, efficiency refers to the 
cost as it means "doing the thing right" not doing the right thing but this act opposes the constrains of the conservation of the heritage items as these items have to be treated in a sensitive manner as internationally. The leading role ${ }^{1}$ in developing and promoting heritage conservation principles sets out some common principles that guide conservation work, as the key principle of conservation work is the importance of understanding the significance of a place before making any decisions about its future. Otherwise, the heritage significance can be demolished [1, 2]. So statutory heritage listing not only controls the demolition of listed heritage items, but also limits the degree to which changes can be made to them. Also, legislation requires owners to apply to a consent authority (the local council or the heritage council) before making substantial alterations. And there are many exemptions to this requirement for relatively minor works or those that will have minimal effect on the heritage significance of the place as the aim of the legislation is to achieve a sensible balance between retaining the heritage significance of special places and enabling them to continue to be of use to the owners and the community $[3,4]$.

And there are constrains for the change concerning the relocation, the removing or adding of the items as follows [1]:

(1) Relocation, however, can be a legitimate part of the conservation process where assessment shows that:

- The site is not of associated value as an exceptional circumstance;

- Relocation is the only means of saving the structure;

\footnotetext{
${ }^{1}$ The leading role in developing and promoting heritage conservation principles has been taken by the ICOMOS (International Council on Monuments and Sites), a non-governmental body formed in 1965 under the auspices of UNESCO (United Nations Educational, Scientific and Cultural Organization). As early as 1966, ICOMOS adopted a charter for conservation work (known as the Venice Charter), which set out internationally accepted conservation principles. Following the lead of the Venice Charter, the Burro Charter (prepared by Australia ICOMOS), the New Zealand Committee of ICOMOS has adopted its own charter, the ICOMOS New Zealand Charter.
}

- Relocation provides continuity of cultural heritage value. A new site should provide a setting compatible with cultural heritage value;

(2) The obscured items (the hidden items): the material of a particular period may be obscured or removed if assessment shows that this would not diminish the cultural heritage value of the place. In these circumstances, such material should be documented before it is obscured or removed;

(3) The addition: the only change accepted concerned the installation of electricity, modern plumbing and improved roofing, which were justified on the grounds that they help to protect the historical remains and insure their future use.

So the efficiency is always accompanied by the significance of the heritage items. It must be achieved within effectiveness: doing the right thing with least money or in a sustainable manner.

The most important goal is to obtain an end result that approaches the original stone, brick or concrete as identical as possible (color, texture, elasticity, porosity, dilatation and shrinkage, etc.) and to limit possible future side effects (chemical or mechanical). Selection of which type to use will depend on:

- compatibility of both materials (the existing stone and the repair-mortar) in all regards;

- "treatability" of the work (geometrical or formal complex) and the workability of the mortar (hardening period/level of plasticity);

- work and climate conditions (inside, outside, warm, humidity) [5].

\subsection{Types of the Deterioration of the Elements That Need Reinforcement}

Most factors causing deteriorations to the elements forming the buildings vary between humidity, the rising ground water table, the over loaded sewage systems and the poor techniques used in the restoration process that had its impact on the restored parts, but the deteriorations can be classified according to their seriousness as the inconsequential damage, the 
repairable damage and the overall repair or replacement [6].

\subsubsection{Inconsequential Damage}

Problems of this type are of no immediate structural concern, but they do need attention for the structure to maintain its durability. Examples of such damage are:

(1) decomposition of lime mortar between stone courses and between adjacent stone blocks in walls. This is probably due to loss of adhesion of the mortar to the adjoining stone over time, combined with some slight relative motion (Figs. 1-3);

(2) partial wear of blocks made of friable or weak sandstone, mostly due to weathering (Fig. 4);

(3) desiccation of new replacement stone blocks because of their poor quality and high porosity (Fig. 2);

(4) deterioration of stone and masonry blocks because of probable chemical aggression of gypsum plastering or air pollution;

(5) old sporadic vertical fissures in thick stone walls (Fig. 5);

(6) slight old separation at intersections of walls.

For example, the deterioration of the northern wall of al-Azhar Mosque due to the humidity and the wind factors in 1915 is shown in Fig. 1. And another example: the lime stone blocks that rapidly deteriorated but marble blocks remain stable at al-Azhar Mosque in Cairo, Egypt in 1992 shown in Fig. 2 [6].

Also, the disintegration of lime stone caused by salt deposits from ground water in al-Ghuri in Cairo, Egypt in 1992 (Fig. 3) [6], and the stone and masonry failure caused by the gypsum plastering were used for restoring the wall of Qawsun Gate (Fig. 4) [6].

\subsubsection{Repairable Damage}

In this category, damage or problems needs prompt action to avoid potential failure under any future overload or soil subsidence. Examples include:

(1) disintegration of the lime mortar between stone blocks of arches and domes;

(2) through cracks in stone blocks of lintels;

(3) continuous vertical separation between stone blocks;

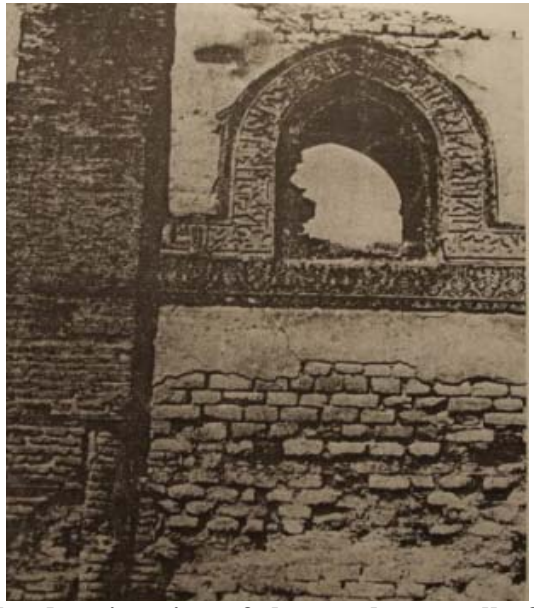

Fig. 1 The deterioration of the northern wall of al-Azhar Mosque due to the humidity and the wind factors in 1915 [6].

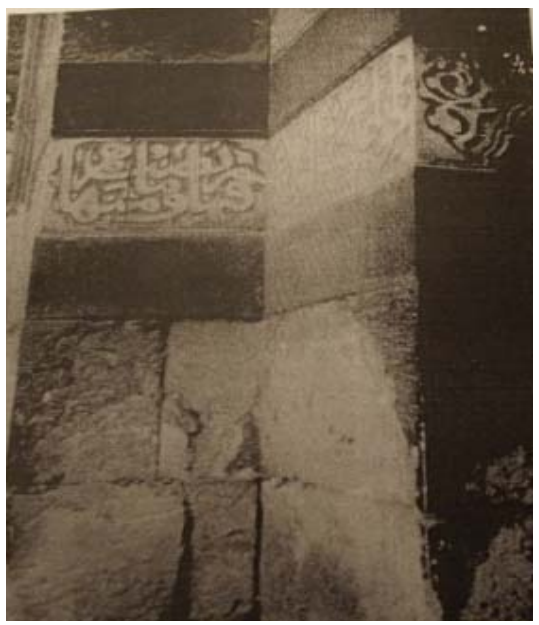

Fig. 2 Lime stone blocks are rapidly deteriorated but marble blocks remain stable at al-Azhar Mosque in Cairo, Egypt in 1992 [6].

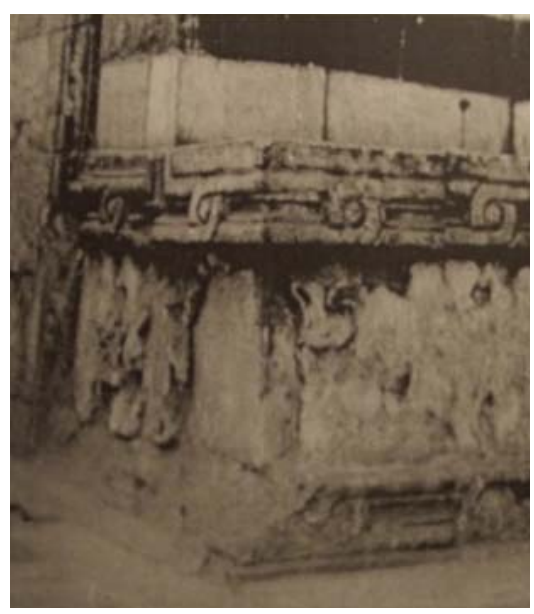

Fig. 3 Disintegration of lime stone caused by salt deposits from ground water in al-Ghuri in Cairo, Egypt in 1992 [6]. 


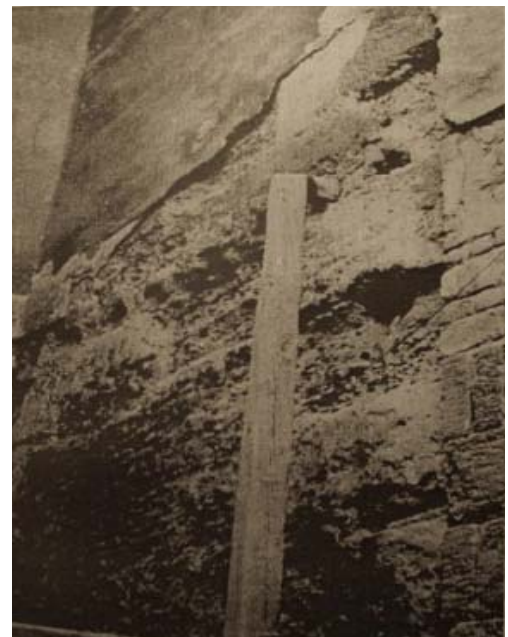

Fig. 4 Stone and masonry failure caused by the gypsum plastering used for restoring the wall of Qawsun Gate [6].

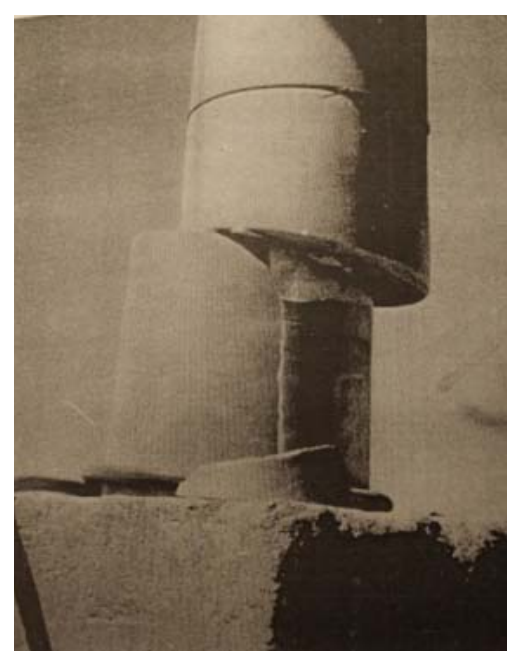

Fig. 5 Local failure in a marble column in Sarghatmash Mosque in Cairo, Egypt after the earthquake in 1992 [6].

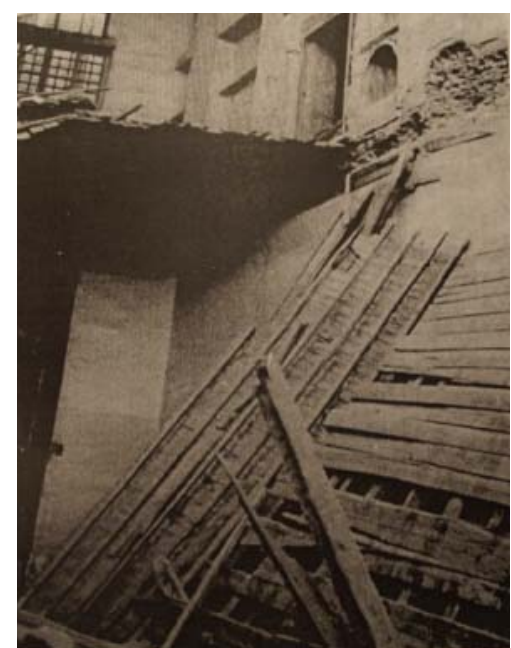

Fig. 6 The collapse of the timper in house of Ali Katkuda after the earthquake in 1992 [6].
(4) active settlement cracks at wall corner;

(5) local failures in slender elements such as minaret marble columns;

(6) disintegration of stones at wall intersections, for example, the local failure in a marble column in Sarghatmash mosque in Cairo, Egypt after the earthquake in 1992 [6].

2.2.3 Overall Repair or Replacement

In this category, structures or parts of structures have already collapsed, or where overall failure is imminent, such as:

(1) severe thrust of domes or arches on abutments or walls;

(2) excessive settlement that has distorted the structure;

(3) tilting and/or displacement of wall corners due to excessive settlement;

(4) disappearance of wooden floors or wall parts in areas where collapse has already taken place.

Examples of such deterioration are: the collapse of the temper in house of Ali Katkuda after the earthquake in 1992 (Fig. 6) [6].

\subsection{Assessing the Efficiency of the Traditional Ways of Reinforcing the Heritage Elements of the Buildings}

There had been various aspects of reinforcement applied on the heritage buildings especially in Egypt. Many of the techniques involved are no longer part of the modern construction industry vocabulary and others are as means of the revivalism of the heritage traditional one.

2.3.1 Reinforcement as Means of Revivalism

This aspect of reinforcement was used commonly when the budget of the restoration process is limited as had appeared in the mission of the German Institute (which represents the German-Egyptian rescue program) as the conservation of the Darb al-Qirmiz since 1973 and completed four buildings after 12 years using simple techniques and traditional materials because of the limited fund and the scarceness of sophisticated restoration equipment, and materials on 
the local market, especially in the early years of the project. So the red brick, stone and timber had been mostly imported. Bonding and plastering was done with mortars composed of slacked lime, sand and the addition of the crushed brick or timber ashes as heritage techniques were revived. For example, masonry covered by salt crystals was cleaned by applying layers of mud, new coats of plaster were reinforced with linen fibers, and brick walls were reinforced with inserted timber beams. Modern materials were only used for restoration of decorative elements, especially painted wood work, metal parts, marble mosaic, and stucco work [6].

But while measuring the efficiency of all the used materials, it seems that they are inefficient as they have a duration time and, at the same time, they can be affected by the environmental conditions.

\subsubsection{Modern Means of Reinforcement}

These means varied between using the resins (epoxy, acrylic, etc.), the externally or internally bonded steel or plates or carbon laminates (carbon fiber reinforced polymers) which is parallel to the existing structures, also the shear walls or bracings are used.

One of the examples of the modern means of reinforcement appeared in the restoration of the dome of Sama Kana Building in Cairo, Egypt (Fig. 7).

As after the problems of flattening the dome and the distortion caused by the settling of the foundation, the dome was supported by wooden scaffolding internally and a steel belt was used from outside. The wood centers were strengthened by epoxy-resins and some of them were replaced. The laths forming a covering under and over them were sewn up with strips of wire netting. A lime mortar, quite similar to the old one in its composition, with the addition of acrylic resins, was applied to the outer surfaces and a moved panel on the extrados allows people to see the restoration work carried inside the dome section.

A concrete beam was fitted inside the thickness of the wall linking the wooden structure of the roof and the dome with the vertical walls.
The shape of the roof square has been strengthened by diagonal iron tie-bars anchored to the concrete beam.

New careful connections of all the joints of the wooden structure and the strengthening of the walls with injections are an improvement of the structure that helped save the monument during the earth quake in October 1992 [6].

But in the presence of the surface, water and sewage water can affect the concrete beams as the steel rust and the masonry will be affected by corrosion as had happened in El Azhar Mosque in 1960 after restoring it but in the presence of such water problem as the used Portland cement contains calcium and aluminum silicates as well as calcium sulfate and some alkaline salts, which had penetrated into porous materials causing damage, such as dark spots, efflorescence and salts crystallization stresses.

Moreover, in all fibrous composite technologies, a proper fiber finishing or application of a coupling agent is essential. These are surface coating applied to the reinforcement to protect it from damage during processing, aid in processing and to promote adhesion to matrix. They can be film forming organics and polymers, adhesion promoters (like saline coupling agents) or chemical modifiers (like silicon carbide on boron fibers).

And these composites vary as their properties which are shown in Table 1.

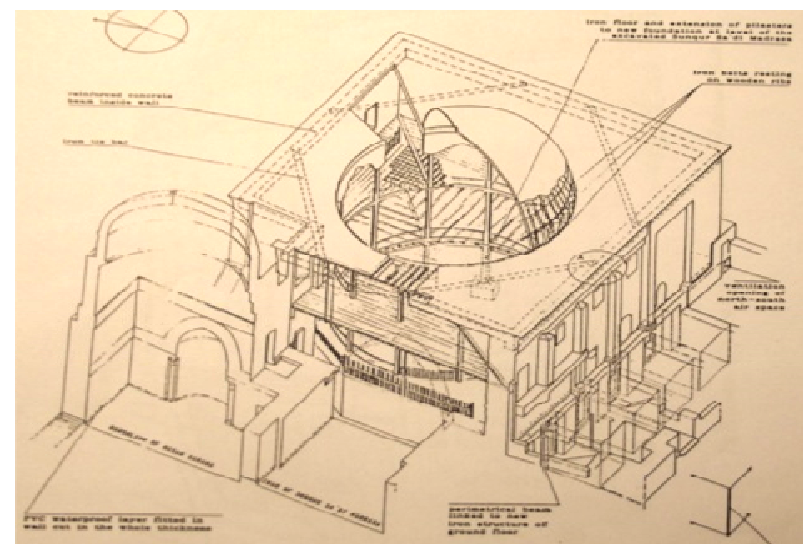

Fig. 7 The dome of Sama Kana Building in Cairo while restoring it [6]. 
Table 1 Types of fibers, their properties and their uses.

\begin{tabular}{|c|c|c|c|}
\hline $\begin{array}{l}\text { Types of } \\
\text { fibers }\end{array}$ & $\begin{array}{l}\text { Common use } \\
\text { fibers }\end{array}$ & Properties & Uses \\
\hline \multirow{5}{*}{$\begin{array}{l}\text { Glass } \\
\text { fiber }\end{array}$} & $\begin{array}{l}\text { E-glass with } \\
\text { boron or } \\
\text { without }\end{array}$ & $\begin{array}{l}\text { - It has low electrical conductivity; } \\
\text { - It is the cheapest glass fiber; } \\
\text { - High tensile strength and modulus with individual filament strengths around 3,500 MPa and } \\
\text { modulus around } 80 \mathrm{GPa} \\
\text { - Elongation-to-break is nearly } 5 \% \text {; } \\
\text { - The ultimate use temperature of E-glass is around } 500{ }^{\circ} \mathrm{C} \text {; } \\
\text { - The corrosion resistance of E-glass without boron is approximately seven times the corrosion } \\
\text { resistance of the boron-containing; } \\
\text { - Boron free E-glasses have approximately a } 10 \% \text { higher dielectric constant than boron } \\
\text { containing E- glasses; } \\
\text { - Density: } 2,620 \mathrm{~kg} / \mathrm{m}^{3} ; \\
\text { - Tensile strength: } 3,450 \mathrm{MPa} \text {; } \\
\text { - Young's modulus: } 81 \mathrm{GPa} ; \\
\text { - Strain to failure: } 4.9 \% \text {. }\end{array}$ & $\begin{array}{l}\text { - E-glass accounts for } 90 \% \\
\text { of the glass fiber market } \\
\text { and is used mainly in a } \\
\text { polyester matrix; } \\
\text { - It stands for "electrical”. }\end{array}$ \\
\hline & ECR-glass & $\begin{array}{l}\text { - These fibers are boron-free with a modified structure to enhance short and long-term acid } \\
\text { alkali resistance; } \\
\text { - Their mechanical properties are similar to E-glass but they have less weight loss based on } \\
\text { sulphuric acid exposure; } \\
\text { - The enhanced corrosion resistance results in an increase in cost. }\end{array}$ & $\begin{array}{l}\text { ECR-glass was } \\
\text { manufactured specifically } \\
\text { to resist acid and alkali } \\
\text { exposure. }\end{array}$ \\
\hline & $\begin{array}{l}\text { S-glass, } \\
\text { R-glass and } \\
\text { Te-glass }\end{array}$ & $\begin{array}{l}\text { - S-glass is } 10 \%-15 \% \text { stronger than E-glass, but is otherwise similar in its properties to E-glass } \\
\text { and R-glass. It is boron free and heat resistance is better than that of E-glass. S-glass fibers } \\
\text { have modified silicate network giving an increase in mechanical properties. S-glass is } \\
\text { typically selected for many structural applications because of its enhanced mechanical and } \\
\text { temperature performance. It should be noted that higher melt temperatures are required for } \\
\text { S-glass, requiring more process energy making these fibers more expensive than E-glass; } \\
\text { - Density: } 2,500 \mathrm{~kg} / \mathrm{m}^{3} \text {; } \\
\text { - Tensile strength: } 4,590 \mathrm{MPa} \text {; } \\
\text { - Young's modulus: } 89 \mathrm{GPa} \text {; } \\
\text { - Strain to failure: } 5.7 \% \text {. }\end{array}$ & \\
\hline & Silica/quartz & $\begin{array}{l}\text { Silica/quartz glass fibers have increasing silicon oxide with enhanced high temperature } \\
\text { performance. }\end{array}$ & $\begin{array}{l}\text { Applications include } \\
\text { communication and } \\
\text { satellite equipment for } \\
\text { protection against electrical } \\
\text { discharges. }\end{array}$ \\
\hline & D-glass & $\begin{array}{l}\text { D-glass fibers are low volume specialist fibers with low dielectric constant which can be } 40 \% \\
\text { lower than E-glass. }\end{array}$ & $\begin{array}{l}\text { They are used in circuit } \\
\text { boards because of their low } \\
\text { dielectric constant. }\end{array}$ \\
\hline \multicolumn{2}{|c|}{ Carbon fiber } & $\begin{array}{l}\text { - Carbon fiber is the reinforcement material of choice for "advanced" composites, Carbon fiber } \\
\text { exhibits excellent fatigue resistance which does not suffer from stress rupture compared with } \\
\text { glass or aramid fibers; } \\
\text { - Untreated carbon fibers do not wet easily, so adhesion to the matrix must be achieved by } \\
\text { mechanical interference coupled with surface treatment and chemical bonding between the } \\
\text { fiber and the matrix of the high conductivity; } \\
\text { - Most carbon fibers are derived from polyacrylonitrile, but for even higher conductivity, fibers } \\
\text { derived from pitch can have three times the conductivity of copper; } \\
\text { - Carbon fiber properties depend on the structure of the carbon used. Typically they come } \\
\text { defined as standard, intermediate and high modulus fibers. }\end{array}$ & $\begin{array}{l}\text { - Carbon fibers are supplied } \\
\text { in tows; } \\
\text { - Carbon reinforced } \\
\text { composites are often used } \\
\text { for low strength } \\
\text { applications requiring } \\
\text { good electrical properties. }\end{array}$ \\
\hline \multicolumn{2}{|c|}{ Aramid fiber } & $\begin{array}{l}\text { Aramid fibers have the highest strength to weight ratio compared to other commercially } \\
\text { available fibers. Kevlar manufactured by DuPont is one familiar brand name. Aramid fiber } \\
\text { exhibits similar tensile strength to glass fibre, but can have modulus at least two times as great. } \\
\text { Aramid is very tough allowing significant energy absorption but compared to carbon, it is lower } \\
\text { in compressive strength and has poorer adhesion to the matrix. It is also susceptible to moisture } \\
\text { absorption. Aramid fiber properties depend on the structure used and can be tailored for high } \\
\text { toughness or high modulus. }\end{array}$ & \\
\hline \multicolumn{2}{|c|}{ Boron fiber } & $\begin{array}{l}\text { Boron fiber actually predates carbon fiber as a high-modulus reinforcement material. The cost } \\
\text { of boron, however, has seen its demise, with its replacement with carbon fiber. They do not } \\
\text { differ greatly from glass fiber in tensile strength, but can have modulus five times that of glass. } \\
\text { Since the objective of reinforcement is to stiffen, this is a significant advantage. Their use is } \\
\text { confined to niche markets where the modulus advantage over carbon fiber is critical. }\end{array}$ & \\
\hline
\end{tabular}




\section{Assessing the Role of the New Technology in Reinforcement and Its Relation to the Ornaments}

This section of the study will demonstrate the assessment of the new trends of reinforcement and the relation between these new trends and the ornaments.

\subsection{Role of the New Technology in Reinforcement}

Nowadays, new technologies have appeared as means of reinforcement and they vary between the smart materials and the nanomaterials to represent smart aspects for solving many problem, as new properties for materials are gained by such technologies making them act in a form of a magic solution as they do not affect the main feature of any object they deal with but they provide it many extra properties.

\subsubsection{Smart Materials in Reinforcement}

It may be discussed as a substitute for traditional materials in many components and functions because of their features and characteristics distinguished them from the most traditional materials used in the architecture. As some smart materials show stiffness by means of the electro rheological and magneto rheological, the potential difference could change the properties of the materials [7], as shown in Table 2.

\subsubsection{Nanoparticles and Nanomaterials in} Reinforcement

Nanotechnology is the art of new sophisticated technological process, which is based on using of very small particles of material either by themselves or by their manipulation to create new large scale materials when their physical, mechanical and chemical properties become more affected. It helps to improve existing products rather than creating completely new products.

The nano particles played a great act in the reinforcement of some constructional materials like concrete, steel and glass. Concrete becomes stronger, more durable and more easily placed, steel tougher and glass self-cleaning. Increased strength and durability are also part of the drive to reduce the environmental footprint of the built environment by the efficient use of resources [9].

The implications of nanotechnology in building sector are introducing new potentialities for used materials. They lend building materials and surfaces entirely new physical and mechanical properties. The key characteristic is not the material itself but the size of the particles. These are responsible for properties such as fire-resistance, durability and strength.

The used nano-sized particles that stand out in their application to construction materials are CNTs (carbon nano tubes), nano-silica, copper nano particles and the nano fibers of wood [10].

\subsubsection{Carbon Nano Tubes}

The current stars of the nano-world are another variety of the fullerenes known as carbon nanotubes, or simply nanotubes for short, and were discovered in 1991 by Professor Sumio Lijima at the electronics concern NEC in Tsukuba, Japan. Nanotubes consist of SWNTs (single-walled carbon tubes) or MWNTs (multiwall carbon tubes) of rolled layers of graphite. They have a diameter of between one and a few nanometers and can be several nanometers long. They have a tensile strength far in excess of steel, yet are flexible and lighter. Their thermal conductivity is also higher than any other known material, exceeding that

Table 2 Mapping of smart materials to architectural requirements [8].

\begin{tabular}{lll}
\hline Architectural requirement & Relevant material characteristic & Smart material application \\
\hline & $\bullet$ & $\bullet$ Piezoelectric; \\
Control of structural vibration & $\bullet$ Euler buckling; & $\bullet$ Magneto rheological; \\
& $\bullet$ Strain sensing. & $\bullet$ Electro rheological; \\
& & $\bullet$ Shape-memory alloys; \\
\hline
\end{tabular}


of diamond. Their key properties - great strength coupled with low weight - are predestined for use in future composite materials. Nanotubes can act as semiconductors or as conductors. Their electric conductivity is excellent, and as such nanowires are of great interest for electronic applications such as minute circuits and a generally more efficient use of electricity. The mechanical properties described are, however, only attained when the atomic structure of the nanotubes is faultless. Any defects result in impaired performance. A particularly ingenious variant developed for certain applications is filled with nanotubes which are great strength coupled with low weight. As they are up to 50 times stronger yet 10 times lighter than steel [9].

One of the examples for such material is the Shimizu TRY 2004 mega-city pyramid (Fig. 8) which would house 750,000 people of height 2,004 $\mathrm{m}$ high so the proposed material used in the structure is nano carbon as it represents a super-strong light weight material.

Another example is the carbon tower Peter Testa (Fig. 9) as this project is a 40-story skyscraper which is proposed to be the lightest and strongest building so it will be made of composites mostly carbon fibers, glass fibers as they are strong and light weight and easily molded into an almost endless variety of shape, and the carbon fibers will form 40 strands about 1 inch wide and 650 feet long that are arrayed in a helicoidally pattern.

Moreover, carbon nanotubes show that, not only do these materials significantly increase the compressive strength of cement mortar specimens, they also change their electrical properties which can be used for health monitoring and damage detection. SCC (self-compacting concrete) is one that does not need vibration in order to level off and achieve consolidation. This represents a significant advance in the reduction of the energy needed to build concrete structures and can offer benefits of up to $50 \%$ in labor costs, due to a sustainability issue that is being poured up to $80 \%$ faster and having reduced wear and tear on formwork.

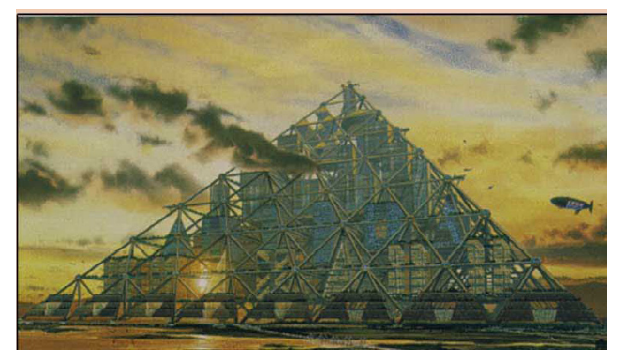

Fig. 8 The Shimizu TRY 2004 mega-city pyramid.

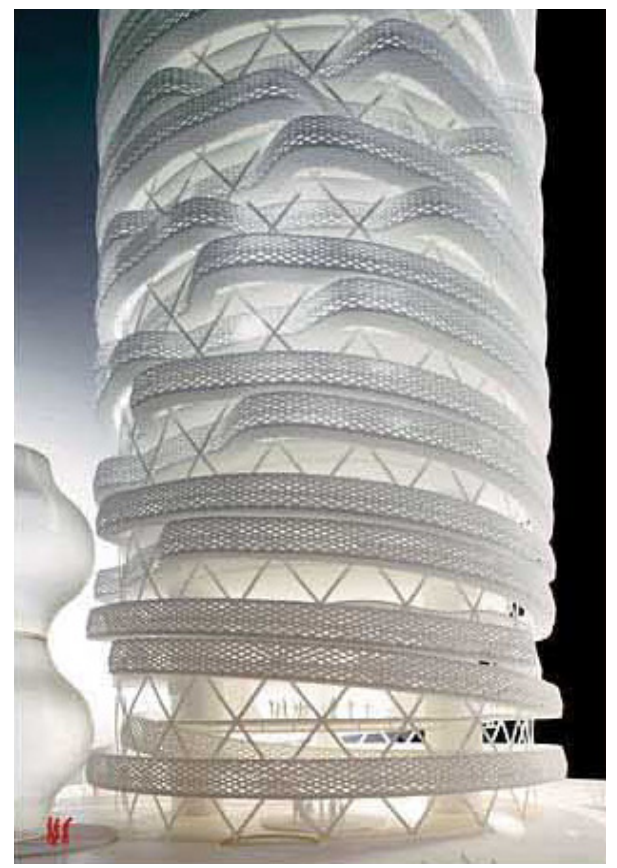

Fig. 9 Carbon tower Peter Testa.

Nanoparticles are used to penetrate and close small cracks on the concrete surface and, in strengthening applications, the matrices form a strong bond between the surface of the concrete and the fiber reinforcement. The ability of the samples to sustain load after cracking is greatly improved by the carbon tows and both the matrix and the interface are durable under wetting, drying and scaling (scraping) conditions.

But nanotubes are always mixed with other materials or applied to surfaces. Additional work is needed in order to establish the optimum values of carbon nanotubes and dispersing agents in the mix design parameters [9].

\subsubsection{Nano-Silica}

Nano-silica's addition to cement based materials can lead to improvements in durability and the compressive 
strength of the refined material (1 to 6 times higher at different ages). For over 80 years, the micro silica has been used widely to be added to concrete to give it high compressive strength and water and chemical resistance.

At the same time, the "ethyl-ortho-silicate" resin plays an important role in surface consolidation of stone as it is available in $75 \%$ up to $100 \%$ (solvent free) concentration. One of the most determinative characteristics is given by the penetration depth of the liquid into the stone surface (and of course the porosity of the stone material) to obtain better and deeper penetration, one suggests "spray-flow" technique (i.e., repeated flow down of the liquid up to full saturation of the stone surface).

\subsubsection{Copper Nanoparticles}

Copper nanoparticles reduce the surface unevenness of steel which then limits the number of stress risers and hence fatigue cracking (Figs. 10 and 11).

\subsubsection{Nanotechnology and Wood}

Wood is composed of nanotubes or "nano fibers", namely, lignocellulosic (woody tissue) elements which are twice as strong as steel. Harvesting these nano fibers would lead to a new paradigm in sustainable construction as both the production and use would be part of a renewable cycle. Some developers have speculated that building functionality onto lignocellulosic surfaces at the nanoscale could open new opportunities for such things as selfsterilizing surfaces, internal self-repair and electronic lignocellulosic devices. These nonobtrusive active or passive nanoscale sensors would provide feedback on product performance and environmental conditions during service by monitoring structural loads, heat losses or gains, temperatures, moisture content, decay fungi and loss of conditioned air. Due to its natural origins, wood is leading the way in cross-disciplinary research and modeling techniques which have already borne fruit in at least two areas. Firstly, BASF has developed a highly water repellent coating based on the actions of the lotus leaf as a result of the incorporation of silica and alumina nanoparticles and hydrophobic polymers. And secondly, mechanical studies of bones have been adapted to model wood, for instance, in the drying process as shown in Fig. 12 [10].

\subsection{Relation between the Ornaments in the Heritage Buildings and the Role of Reinforcement}

Nowadays, most of the global high rise buildings refer to the exoskeleton to glorify the natural lighting and the sense of the free slabs. As this skeleton presents means of ornaments, at the same time, it refers to the reinforcement of the buildings as shown in the O-14 Tower in Dubai, by Reiser + Umemoto, who uses a concrete shell to provide an efficient structural exoskeleton (Fig. 13) [11].

Referring to the heritage buildings, the ornaments sometimes represent means of structural elements as shown in the muqarnas vault, Bishiriya Madrasa in Baghdad in 1255, as the muqarnas elements are formed of terracotta panels decorated with Arabesques which represents the Abbasid architecture (Fig. 14) [12].

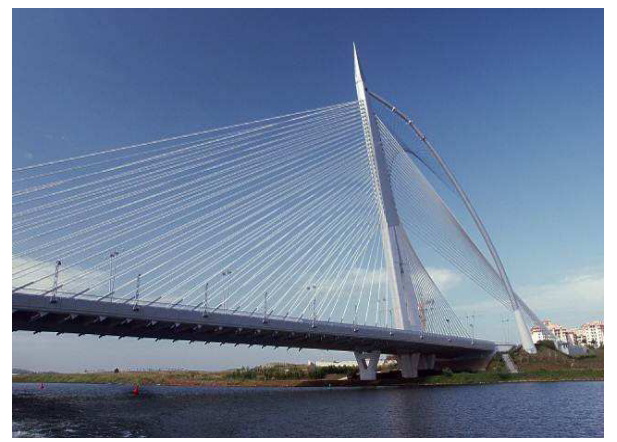

Fig. 10 Seri Wawasan Bridge, Putrajaya (Malaysia's administrative centre).

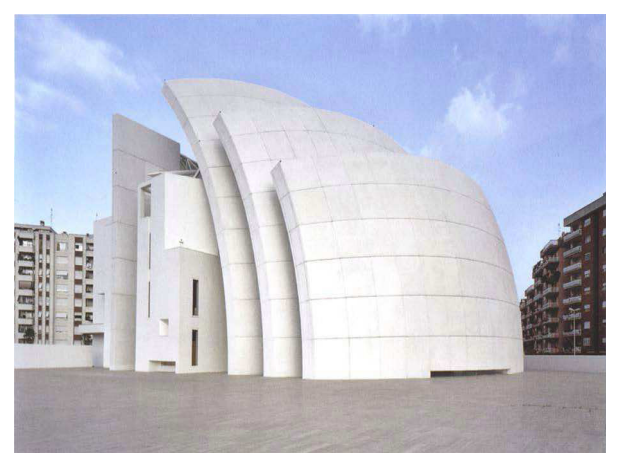

Fig. 11 Jubilee Church, Rome, Italy, Richard Meier, 2003, (TX Millenium, TX Active, photocatalytic cement) [9]. 

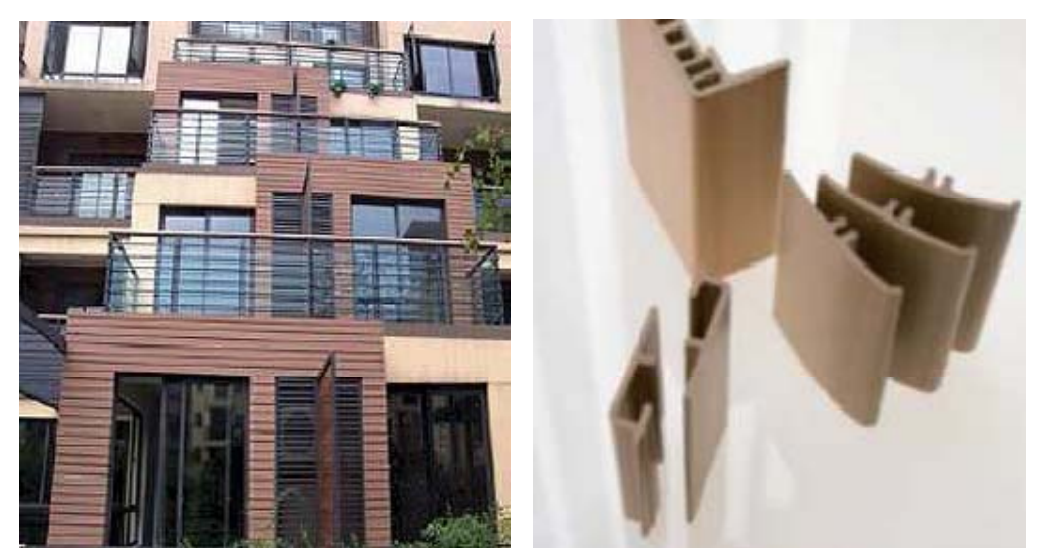

Fig. 12 Wood-plastic composites carbon nanofibers and nanoclayes improve stiffness and are less-toxic alternative to traditional treated timber [12].

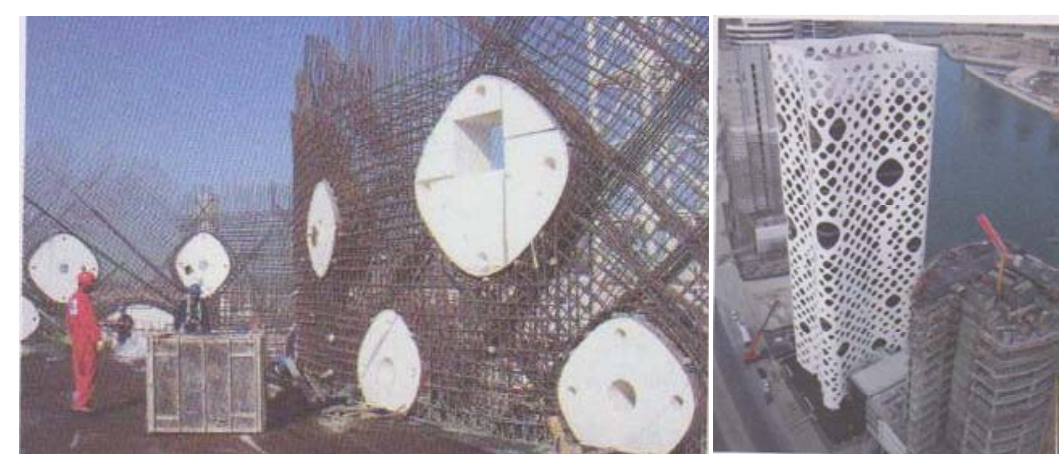

Fig. 13 The 0-14 Tower in Dubai, by Reiser and Umemoto [11]. To the left, the exoskeleton seems to be under construction, while to the right, it seems to be completed.

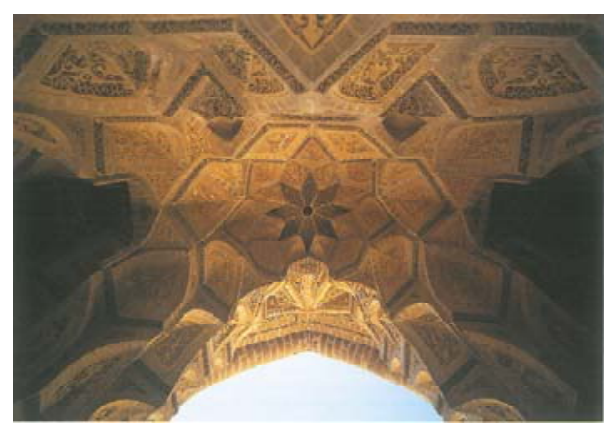

Fig. 14 Muqarnas vault, Bishiriya Madrasa in Baghdad in 1255 [12] .

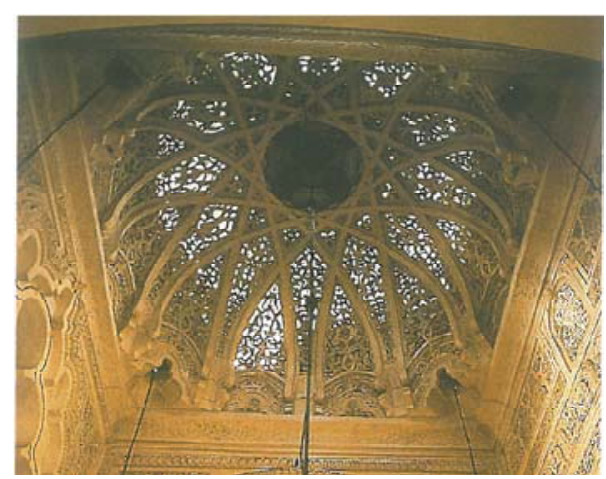

Fig. 15 Dome of the Great Mosque of Tlemcen [12].
Another example is shown in the dome of the Great Mosque of Tlemcen, as the ribbed dome represents a collection of multiple arches and the space between them is filled by peneferated ornaments [12] as shown in Fig. 15.

Sometimes there are special ornaments that take place in the building in different positions as that could play a role in supporting the structural elements as an outer shells or belts for support, the walls, the columns, the roofs, the ceilings, as most of the heritage buildings especially in the Arabian town refer to the decorative art which use the stucco decoration that is related to the Samarra style in which the field is divided by decorated band containing recognizable leaves growing from veins, where the stucco is a material made of gypsum, lime, sand and water used while still wet for architectural decoration, stucco dries very quickly in the sun but is not waterproof. It could either be applied straight onto the building or used in prefabricated 
panels, which were then fixed to the building [12].

Such stucco appeared on the columns of the palaces, the castles, the mosques as shown in Mosque of Nayin, mid-10th century, in the central Iranian town. It is a good example of a provincial Abbasid mosque, the decorated patterns used are called stucco in a variant of the Samarra styles and this shows how the metropolitan style was adapted in provinces (Fig. 16) [12].

Some stucco ornaments appeared on the minarets and the domes as shown in the high Mamluk minaret in Mausoleum of Qaitbai (Fig. 17), 1472-1474, and the impressive domes of Sultan Barsbai are complex in the eastern cemetery of Cairo (Fig. 18), 1432.

The stucco ornaments appeared also on the walls of the buildings especially on the arches of the doors as they appeared to be penetrated as shown in the facade of the Almohad Palace in Seville in the 2nd half of the 12th century called "The Yeso Patio", as the pattern used in the portico entrance and its envelope seem to be reached in decorations, the pointed arches whose archivolt is made up of little branches with leaves, which show the plaster or stucco courtyard (Fig. 19).

Also, the walls of ornaments came semi penetrated or bulky as shown consecutively in the southern palace wing of Aljaferia of Zaragoza, 2nd half of the 11th century outside as the portico whose arcade comprises

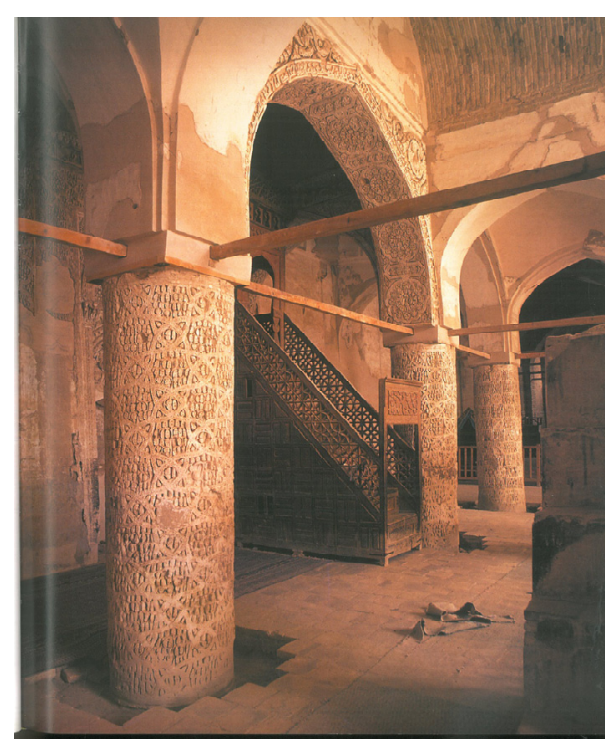

Fig. 16 Mosque of Nayin, mid-10th century, in the central Iranian town [12].

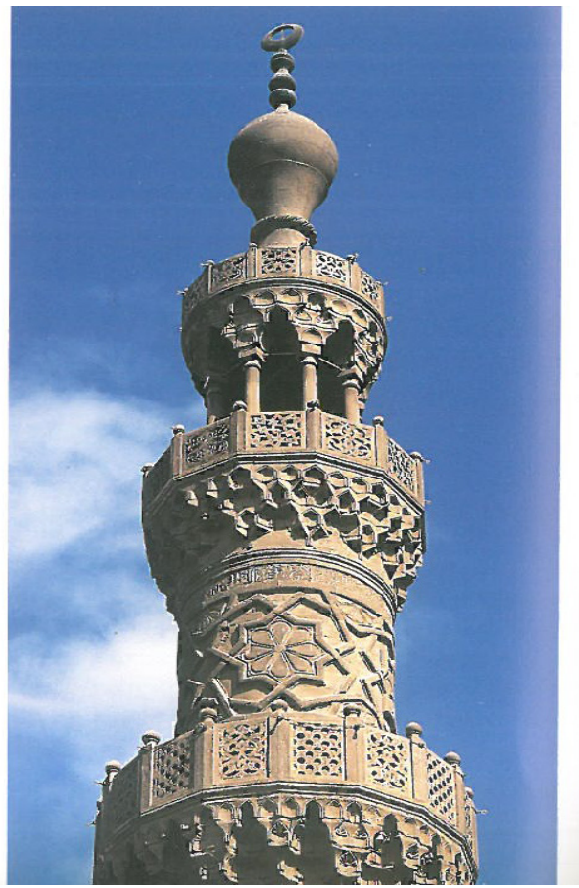

Fig. 17 Mausoleum of Qaitbai, 1472-1474 [12].

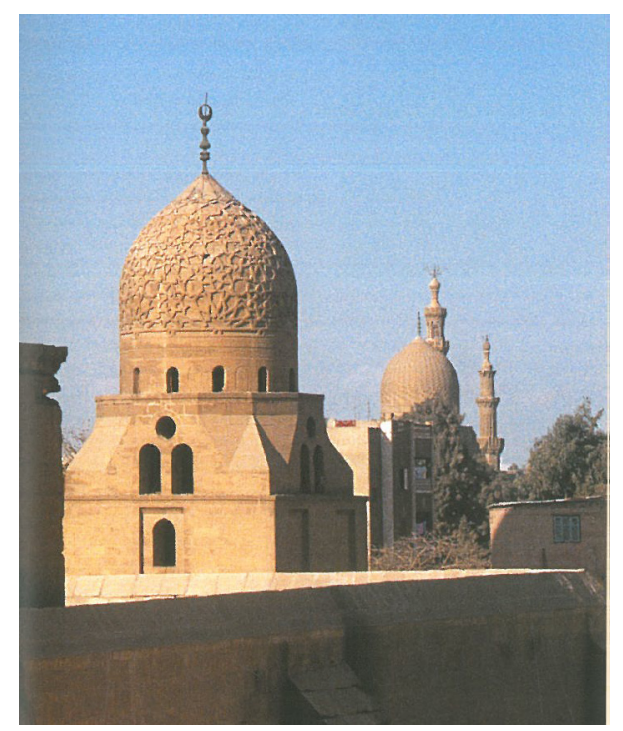

Fig. 18 The complex of Sultan Barsbai in the eastern cemetery of Cairo, 1432 [12].

interlaced semicircular arches with unique ornamented faces. As the ornamentation is constructed from a repeated framing of the basic elements forming the arches, and is a typical taifa period innovation (Fig. 20). And the façade of the most beautiful Mudejar palaces in Spain is shown in Fig. 21.

Ornament patterns have appeared on the arches as shown in the archivolt over the first gateway of the 
Aleppo citadel which is decorated with figurative relief as the motif traditionally used in the art of the Anatolian Seljuks and Artuqids who decorated many citadels, city walls and caravanserais with similar figurative images (Fig. 22).

Also, ornaments appeared on the walls of the Mihrab as shown in the Great Mosque of Koairouan, as it is adorned with perforated wall panel (Fig. 23).

\section{Results and Discussions}

Selection of materials for use in architecture is always based on various criteria as performance and cost have obvious role in this selection, but final

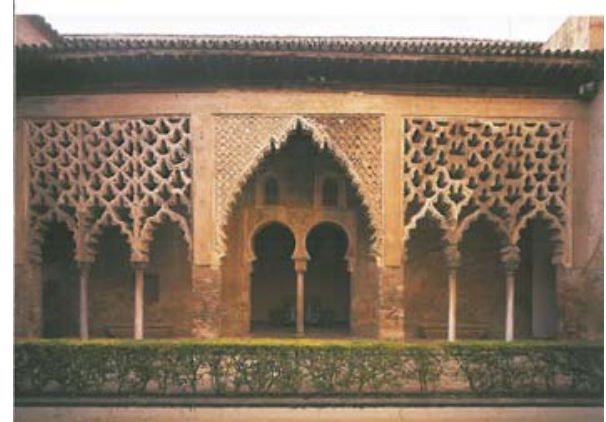

Fig. 19 The façade of the Almohad Palace in Seville in the 2nd half of the 12th century [12].

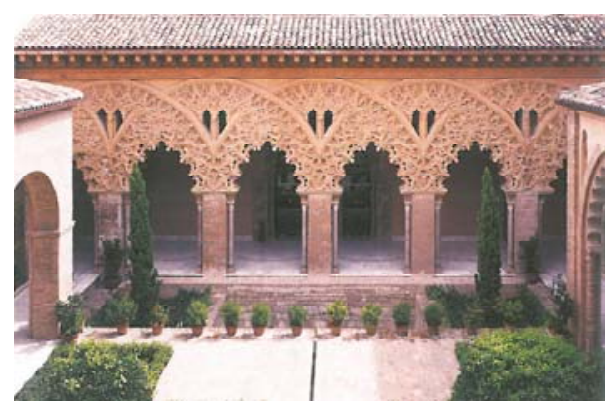

Fig. 20 Southern palace wing of Aljaferia of Zaragoza in the $2 n d$ half of the 11th century [12].

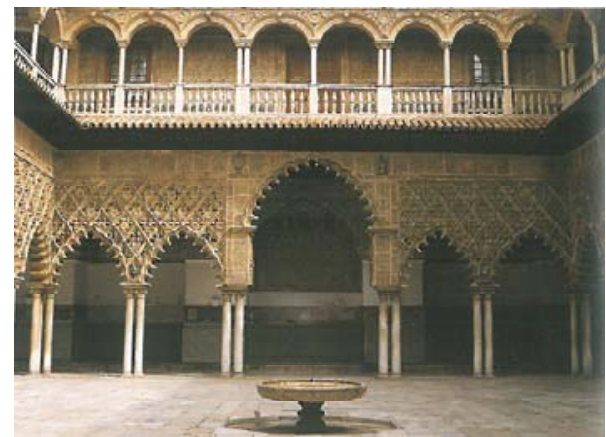

Fig. 21 Alcazar, Seville 1530-1369, is one of the most beautiful Mudejar palaces in Spain [12].

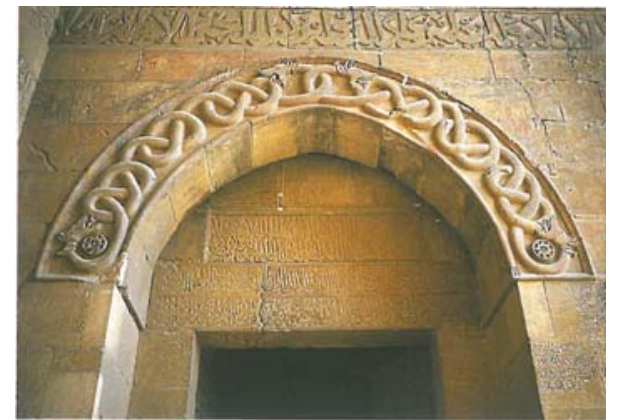

Fig. 22 The archivolt over the first gateway of the Aleppo [12].

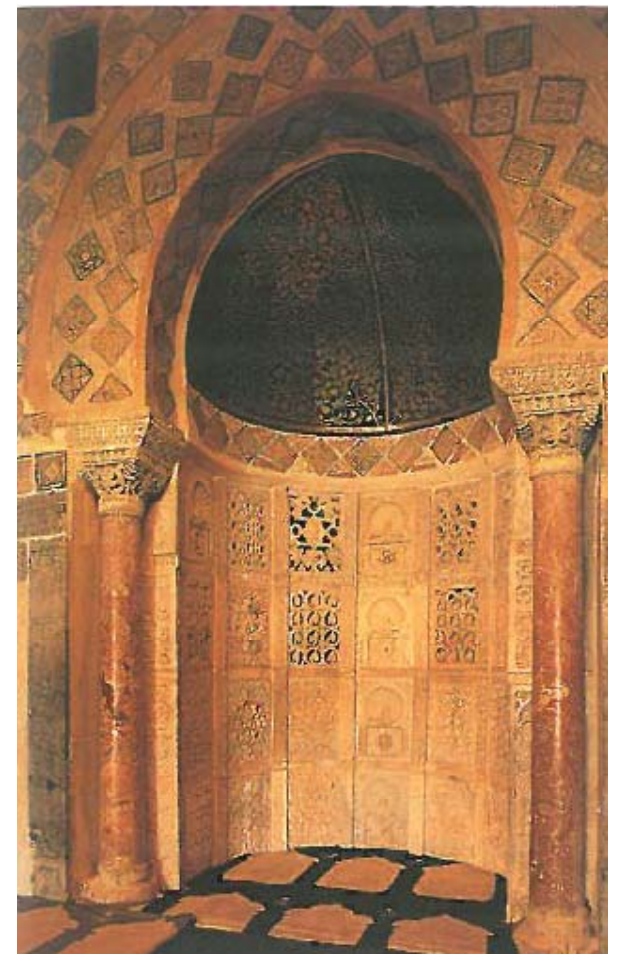

Fig. 23 Mihrab of Great Mosque of Koairouan [12].

selection is often done based on appearance, beauty and aesthetic, ease of construction with regard to human resource skills, availability of local or regional, as well as materials used in the building which are in the near place.

In the meanwhile, efficiency means both low weight and low cost because any fibers which do not carry much load could probably be removed.

But many progressive materials have emerged for preparing the fastest visual appearance and thus providing appropriate tools for interior and exterior of buildings. Thus, modern architects often think about 
materials as a part of the composition of design through which materials can be selected and accepted as level of structure or combination and visual. It is in such an atmosphere and environment that many people reached to the approaches of using smart materials.

Nanotechnology introduces promising economical solutions and products to achieve reliable sustainable environment. And the development of nanotubes is continually being optimized as high-quality nanotubes can now be produced much more cheaply and in large quantities. Although nanotubes can now be produced comparatively economically, they are still too expensive for use in large quantities.

Concerning the corrosion problems in concrete products, nanotechnology can offer smart solutions providing coatings that respond to external agents with a "response" that can repair or prevent damage.

Moreover, nanoparticles are reducing the effects of hydrogen embrittlement and improving the steel micro-structure through reducing the effects of the inter-granular cementite phase. The addition of nanoparticles of magnesium and calcium makes the HAZ (heat affected zone) grains finer in plate steel and this leads to an increase in weld toughness. Two relatively new products that are available today are Sandvik Nanoflex (produced by Sandvik Materials Technology) and MMFX2 steel (produced by MMFX Steel Corp). Both are corrosion resistant, but have different mechanical properties and are the result of different applications of nanotechnology. Sandvik Nanoflex has both the desirable qualities of high strength and resistance to corrosion. MMFX2 steel has a modified nano-structure that makes it corrosion resistant and it is an alternative to conventional stainless steel, but at a lower cost. Moreover, the nanomaterials while added to concrete reduced need for maintenance (easy to clean, longer cleaning intervals) and/or operational upkeep.

So by the effort gained by scientists in materials, moreover by the role the ornaments play in reinforcement in the latest era, we can prove that ornaments can play a great role in the reinforcement process in the heritage buildings especially while promoting their presence in several positions can be responsible for reinforcement.

\section{Conclusions}

Before planning alterations or other changes to heritage items, it is necessary to first understand the reasons for its heritage status. Why is it significant? What is its historical context and history of its development? Is it a fine example of an important class of items? Does the community value the place? Does it inform us about our cultural identity? As these factors determine how an item can be changed without negatively affecting its heritage value and what type of heritage management is appropriate.

Thus, even with the limited funds available, a strategy must be agreed upon that will insure protection of all the indexed monuments. But for undertaking complete conservation, some priorities must be set that would systematically direct effort and recourses.

Properties of the new materials need to be compatible with that of the historic materials so that the new materials do not damage the historic ones. Compatibility of historic character, on the other hand, is more subjective and based upon similarity of visual characteristics such as color, size, texture, scale, mass, proportion, configuration, rhythm, ratio of solids to voids, ornamentation, details, etc.. If few or none of the characteristics of the new material harmonize with the historic materials, the effect may be very jarring and detract from the artistic and architectural expression of the historic resource. If all of the visual characteristics are matched, it becomes very difficult to distinguish what is historic and what is new.

Replacement of missing parts of the design must be based on physical or photographic documentation, not conjecture. 


\section{References}

[1] Bowron, G., and Harris, J. 1994. "Guidelines for Preparing Conservation Plans, New Zealand Historic Places Trust.” In The Conservation Plan: A Guide to the Preparation of Conservation Plans for Places of European Cultural Significance, edited by Kerr, J. S. Sydney: National Trust of Australia.

[2] NSW (New South Wales) Heritage Office. 1996. "Heritage Information Series: A Guide to the Heritage System.” Accessed January 1, 2013. http://www.heritage.nsw.gov.au.

[3] Sydney Water. 2009. Veteran Hall Conservation Management Plan, Archaeological Site, Prospect. Unpublished report based on a study conducted by Archaeology and Heritage Pty Ltd.

[4] Heritage Council of New Wales. 2009. Assessing Significance for Historical Archaeological Sites and Relics. Australia: Heritage Council of New Wales.

[5] De Naeyer, André. 2000. New Materials for Safeguarding
Cultural Heritage. Egypt: The American University in Cairo Press.

[6] Jere, L. B. 1995. The Restoration and Conservation of Islamic Monuments in Egypt. Egypt: The American University in Cairo Press.

[7] Addington, M., and Schodek, D. 2005. Smart Materials and New Technologies for the Architecture and Design Professions. Britain: Architectural Press.

[8] Schwartz, M. M. 2002. Smart Material-Encyclopedia. New York: A Wiley-Interscience Publication.

[9] Leydecker, S. 2008. Nano Materials in Architecture, Interior Architecture and Design. London: BirkhauserVerlag AG.

[10] Mann, S. 2006. Nanotechnology and Construction. Nanoforum report.

[11] Dunn, N. 2012. Digital Fabrication in Architecture. London: Laurence King Publishing.

[12] Hattstein, M., and Delius, P. 2007. Islam Art and Architecture, edited by Ullmann, H. F. Accessed January 1, 2013. http://www.ullmann-publishing.com. 